soap and warm water and, in the cases of the men, shaved; the region where vaccination was to take place was then well rubbed with hot boric acid solution (saturated) and afterwards dried with boric lint. The vaccine was placed on the skin in three places and the epidermis was scratched through the vaccine with a blunt lancet; hardly any blood was perceptible, merely a slight discolouration appearing. The ages of the persons revaccinated were between 15 and 65 years, and all ranks of life were represented, from the higher official at $\$ 1000$ a year to the engineer's labourer at $30 s$. a week. In these cases and in a large number of others I have had no failure, every case, in all sorts and conditions of men and women, taking well without undue inflammation or enlargement of glands. The women have all been vaccinated on the shoulder at their own request and have as a consequence suffered much more than the men who have been vaccinated on the outer side of the left forearm where the vesicles cause little inconvenience.

I have carefully tested the results of the use of shields or covering of any kind during the last three months and I am confirmed in my previous conviction that every appliance of the sort is injurious and harmful, the inflammation being increased by heat or pressure or by both; great pain is caused by lint sticking to the vesicles, and I have especially noticed that the wire guards by circumscribing the area of the swelling cause very much increased suffering. I have had the best results when the following directions have been carried out : the undervest sleeve should be turned up and nothing worn under the sleeve of the white shirt which is always very loose; where a coloured shirt is worn, a piece of clean, soft, old cambric handkerchief should be tacked to the inside of the coloured sleeve. The vesicles are in this way hardly touched by the sleeve and the arm is kept cool. The only application I recommend is a liberal and frequent dusting with vinolia powder and $I$ find that with these precautions the vesicles are, as a rule, dry and unbroken.

In large offices there will always be a certain number of conscientious objectors. When I began at the Ocean Offece many declined to be vaccinated, others went to private vaccinators, but when the results of the arms were seen, everyone came to me ; and I mention this as I feel sure that the results were due to careful antiseptic methods, the lancet being sterilised with boiling water between each separate vaccination.-I am, Sirs, yours faithfully, ALBERT BenthaLt, F.R.C.P. Edin.

Tavistock-square, w.C., Jan. 12th, 1902.

\section{THE SANITARY CONDITION OF LEICESTER INFIRMARY.}

\section{To the Editors of THE LANCET.}

Sirs,-As I notice an article in THE LANCET of Jan. 11th, p. 113, on the sanitary condition of Leicester Infirmary, summarising the results "of a joint conference between the weekly board and the honorary medical staff of the Leicester Infirmary" with respect to my recommendations as to the sanitary condition of that institution, which report agrees with almost all of my recommendations, but in which there is a sentence which you have quoted as follows:-

Sufficient cause has not been shown to justify Professor Corfield's opinion that " the whole of the present drainage arrangements must be condemned and removed entirely and new drains laid, \&c."-

I write to inform you that my reason for giving that opinion was that all the drains tested by the architect or by myself were found to leak badly-a fact which, in my opinion, quite justifies the recommendation, which is, I consider, one of the most important and necessary recommendations in my report. It is nowadays axiomatic amongst sanitarians that the drains, especially those of such an institution, whether inside or outside the building, should be watertight. - I am, Sirs, yours faithfully,

\section{W. H. CORFIELD.}

Savile-row, W., Jan. 15th

\section{ARTIFICIALLY MATURED (?) WHISKY. To the Editors of THE LANCET.}

Sirs,-I notice in THE LANCET of Jan 11th, p. 109, a short annotation on the artificial maturation (?) of spirits. Although no reference is made, I presume the article was partially occasioned by the paper which $I$ read before the Society of Chemical Industry on Monday, Jan. only the aldehydes of the spirits, the higher alcohols, fatty acids, esters and basic constituents remaining untouched. Under no circumstances can I think it very advantageous to leave in aldehydes, especially furfurol, when one considers the work of Curci, Magnan, and Laborde and the later publication of Brunton and Tunnicliffe in T'HE LANCET of Dec. 8th, 1900, p. 1643. As a chemist I should be very glad to know what are the opinions of physiologists on the effect of aldehydes.

I am, Sirs, yours faithfully,

East London Technical College, Jan. 11th, 1902. J. T. HEwITT.

\section{THE DANGERS OF A COMMON COLD}

\section{To the Editors of THE LANCET.}

SIRs,-Dr. H. Willoughby Gardner, in his interesting etter in THE LANCET of Dec. 14th, 1901, p. 1697, advances many striking arguments, but he does not prove his thesis. That there is an infectious cold no medical man who goes about with his eyes open, as your correspondent says, can doubt, but the question is whether this is the only kind. The immunity of isolated bodies of men may show that this is the commoner kind, but as the examples given were lusty adults they do not prove that it is the only kind. Men in good condition seldom catch cold. It is a rare thing for a rowing crew to catch cold, although the coxswain and coach often suffer. The stories are incomplete, for they do not show that this complaint existed in the European settlements where the travellers caught their first cold. In the case of Conway's men it was a "bad cold," and to make the story complete we should know whether bad colds were troubling the little settlement. It would be a curious complication of the question if temporary immunity leads to a worse cold in the end. The immunity in long sea-voyages is better evidence, for the manner of life is that of civilisation, but the ordinary sailor is notorious for his dislike to ventilation; so here it is difficult to understand why colds, if infectious, should die out, for one attack certainly doesnot protect. If the immunity of open-air sanatoriums is complete this is strong evidence, especially as they receive so many catarrhal subjects; but the inmates are living an artificial life and their immunity may be due to other causes than the absence of infection. They eat largely without indigestion, but this does not prove that dyspepsia is due to specific infection. On the whole, the evidence of "no infection, no cold" is strong, but not conclusive.

On the other side is the weight of almost universal opinion in the past, both lay and medical, which ought to go for something, although Dr. Gardner may well smile at the ready histories of exposure given by subjects of an obviously contagious cold; there is similarly a history of an accident connected with most gouty joints. But there is other evidence. Colds, especially amongst the children of the poor, are far more common when the wind is in the east and when, therefore, sudden chills are common. A cold wind will set up eczema and conjunctivitis and therefore it seems probable that it may cause catarrh of the nasal mucous membrane. The phenomenon of what is termed "hay fever" seems to prove that coryza can be set up by causes other than infection, and in many patients a cold much resembles an attack of hay fever. The variations in duration of the incubation period, and of the length of the established attack, the common occurrence of abortive attacks, and the fact that one attack does not protect, all militate against the view that there is a single definite infection.

I feel sure in my own mind that there are persons, for example, who suffer from a cold if they sit in wet boots, and that the symptoms come on within a few hours and are generally ushered in with sneezing; 1 think this happens with sufficient certainty to exclude infection. Of course, there may be an infection generally distributed throughout the civilised world, and a chilled blood-stream may let this enemy in, but this is hardly what is meant when colds are said to be due to a specific infection. More probable is the view that these rapidly developing colds are, like migraine, a disturbance of the vaso-motor system. A recent writer states, I know not on what authority, that "sneezing is a sign of life in the east but of death in the west." It certainly is a sign of a commencing cold in the west, and when this symptom commences almost immediately on exposure to cold it is difficult to believe that infection has any part in 